\title{
An experimental study of acidizing operation performances on the wellbore productivity index enhancement
}

\author{
Elaheh Rabbani ${ }^{1} \cdot$ Afshin Davarpanah $^{2}$ (i) $\cdot$ Mahmoud Memariani $^{1}$
}

Received: 13 August 2017 / Accepted: 14 January 2018 / Published online: 17 February 2018

(c) The Author(s) 2018. This article is an open access publication

\begin{abstract}
The hydrocarbon fossil fuels are considered as the preferable fuels to provide sufficient energies for industrial purposes. Also, extracting oil from the exploration wells might be a concerning issue in the coming decades, and petroleum engineers push themselves into limits ind novel solutions to enhance the oil recovery factor. Wellbore stimulation procedures exert a profound impact on the current production rate enhancement; respect of the way, reservoir productivity index witnesses a steep rise during the production operation and subsequently would virtually eliminate unnecessary expenditures of other methodologies. Appropriate investigation of acidizing procedures and its significant role in the wellbore production enhancement are utterly dependent on the quality and types of additives, types of acid, acidizing operation and types of formation. The objective of this study is to investigate the effect of injected acid in the carbonated reservoir and subsequently its comparison with the acidizing operations model. Therefore, available well-testing experiments are administered to determine the critical reservoir parameters such as skin factor, reservoir pressure, and permeability. Since then by modeling the wellbore condition in the acidizing operation simulator software, the impact of acidizing on the reservoir is simulated. Consequently, the provided information from software is compared with the real data from well-testing operations. As a result, productivity index is increased dramatically owing to successful acidizing procedures.
\end{abstract}

Keywords Matrix acidizing $\cdot$ Productivity index $\cdot$ Well-testing operations $\cdot$ Skin factor $\cdot$ Permeability

\section{Introduction}

Because reservoir characteristics such as reservoir pressure, fluid viscosity have dramatically changed by passing the time and the well is in urgent need of matrix acidizing treatments. Subsequently, alteration of these crucial parameters exerted a considerable influence on the fluid distribution in the reservoir; in respect of the way, permeability reduction in a well directly affects the production rate decrease. Permeability reduction is also known as wellbore damage, and estimation techniques give engineers the chance to overcome the possible reduction factors which might have potentially devastating effects on the production flow rate. Hence, they would find probable solutions to remove the created damages

Afshin Davarpanah

Afshin.Davarpanah@srbiau.ac.ir

1 Department of Petroleum Engineering, Central Tehran Branch, Islamic Azad University, Tehran, Iran

2 Department of Petroleum Engineering, Science and Research Branch, Islamic Azad University, Tehran, Iran or by making new alternative paths to flow the fluid conveniently (Garrouch and Jennings 2017; Guimarães et al. 2017; Hung et al. 1989; Yu et al. 2011). Acidizing is the preferable methodology in petroleum industries due to their high applications and their significant compatibility with any types of the reservoir. These techniques entail matrix acidizing and fracture acidizing; the former operates under the formation fracturing pressure by injecting reactive fluids (commonly hydrochloric acid) to dissolve and disperse the rock while creating highly conductive wormholes while the latter is performed above the formation fracturing pressure. One of the chief aims of this study is to enhance the reservoir permeability or remove the damages around the wellbore; that is to say that, acid treatment would make new channels among interconnected pores with higher permeability than the original permeability (Babaei and Sedighi 2017; Ghommem et al. 2016; Medina et al. 2015). Therefore, the primary purpose of any acidizing operations is to increase well production by removing damages which are caused by drilling operations or improving the physical conditions of the reservoir rock like porosity and permeability. In vertical wells, formation

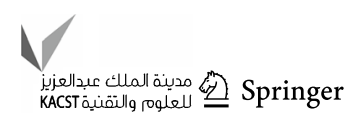


damages lead to decrease in effective wellbore radius and limit the surficial tension with the reservoir. Hence, in horizontal wells with large intervals, wellbore radius does not determine the surficial contact with the reservoir. That is to say that, horizontal interval depth determines the surficial contact of a wellbore with reservoir. Acidizing divided into to three classifications such as acid washing, acid fracturing and matrix acidizing (Ghommem et al. 2015; Msharrafieh et al. 2016; Davarpanah et al. 2018). The dominant influence of temperature on the reservoir parameters describes as the following phenomena:

- Effect of temperature on the porosity: there is no significant impact of temperature on the porosity. The only alteration is the slight increase in bulk volume when the temperature rises to $400{ }^{\circ} \mathrm{F}$ (below $<1 \%$ ).

- Pore volume compressibility: due to the temperature increases up to $400{ }^{\circ} \mathrm{F}$, this parameter rises significantly (below < 21\%).

- Absolute permeability: temperature increase leads to dramatic reduction in absolute permeability (approximately reduce up to $88 \%$ ).

- Relative permeability: however, temperature rise exerts a considerable influence on the increase in oil relative permeability, and water relative permeability does not have an accurate pattern of decreasing or increasing.

- Residual oil saturation: by the increase in temperature, this parameter decreases drastically. But, irreducible water saturation has witnessed a rise in temperature.

Therefore, the influence of temperature increase on the permeability causes a partial change in the physical and chemical properties of the fluid. Also, due to the independence of absolute permeability of the rock from the fluid, this issue might be debated and needs more considerations (Barati and Liang 2014; Sanyal et al. 1974; Schön 2015;
Tiab and Donaldson 2015). Moreover, by increasing the temperature the amount of optimum rate would increase. According to the Wang et al. investigations, at $50{ }^{\circ} \mathrm{C}$ the optimum acid rate is $60 \mathrm{ml} / \mathrm{h}$. And at the $75{ }^{\circ} \mathrm{C}$ the optimum rate is $210 \mathrm{ml} / \mathrm{h}$. Thereby, soaring temperature leads to the small volume of acid injection to achieve breakthrough (Wang et al. 1993).

The optimum amount of acid flow rate is a complex function of temperature, the composition of the rock and distribution of pore sizes which should be taken into account during the acidizing procedures. Although there isn't a stable solution to whether the fast or slow acid rates would be the best solution or not, exceeding from the optimum amount would be a solvable problem by reducing the acid rate to enhance the recovery performances. On the other words, the optimum amount of acid injection rate would vary with the concentration of acid, temperature alteration and rock mineralogy. Due to the findings of Wang.Y et al. rock mineralogy exercises a dominant influence. For example, in dolomite formations, it is in an urgent increase in acid volume and decreases in acid rate to penetrate in the pores than limestone formations (Hassani and Kamali 2017; Qi et al. 2017; Wang et al. 1993).

Tight reservoirs like fractured carbonated reservoir are the most susceptible formations to the matrix acidizing due to their low permeability, and dealing with the complexity of these formations is still a major concern of the petroleum industries (Al-Muhareb et al. 2003; Khalil et al. 2017; Msharrafieh et al. 2006). However, conductivity property of the fractures plays the substantial role in the acid fracturing, regarding the random reactions between rock and acid, and this phenomenon might be difficult to estimate. The factors that would seriously affect this issue are pumping rate of the acid, sufficient length of acidizing propagation, the contact time between acid and rock, closure stress and fluid loss of the acid, etc, and these significant parameters are
Fig. 1 Considerable influence of factors on the acid fracturing (Li et al. 2015)

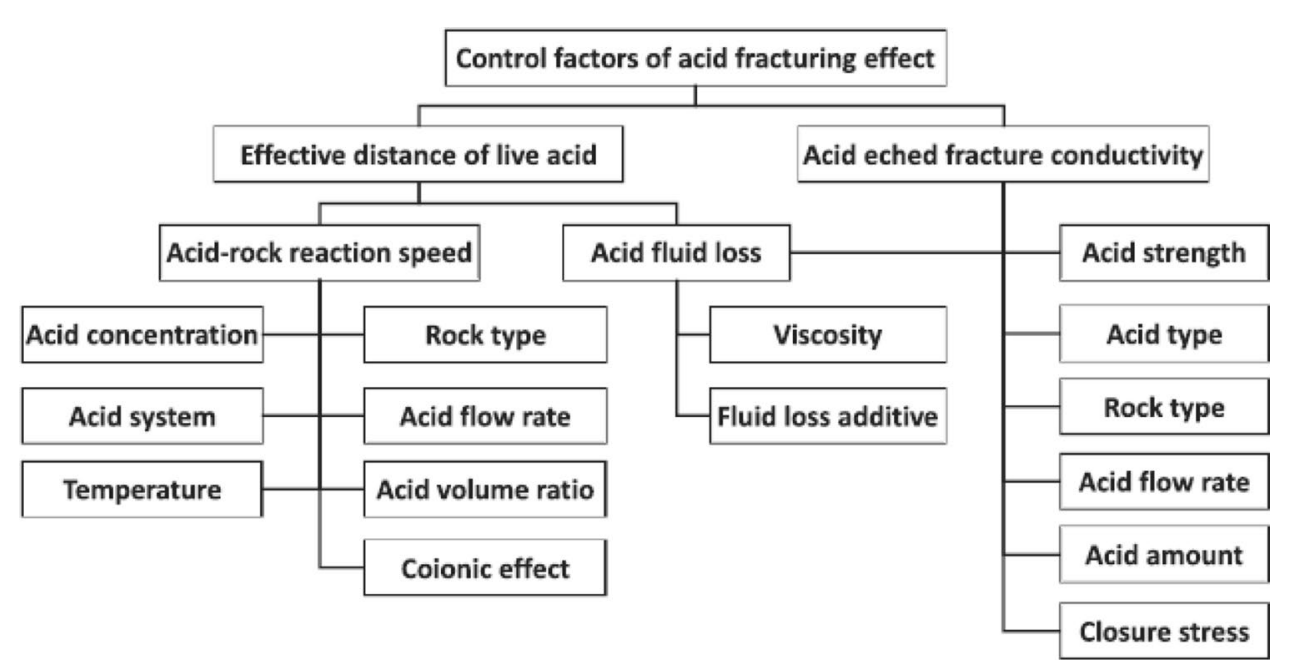


shown in Fig. 1 specifically. Among the mentioned factors, adequate length of acid and fracture conductivity is considered as the important ones. The former is directly influenced by the cracks flow velocity, the speed of rock-acid reaction and filtration properties of the acid; the latter is affected by the closure stress and the shape of edged acid during the reaction of acid and rock. One of the useful types of acid which is used in these reservoirs is the foamed acid with the immense value of viscosity, low rate of fluid loss, retarding agent property for deep wells and etc. (Chengshou et al. 2010; Fufeng et al. 2008; Li et al. 2015).

Mozaffari et al. (2015) proposed that other factors which significantly affect the production rate in fractured carbonated reservoirs are the capillary force of liquid in microand nano-sized channels which might be blocked by the asphaltene. Due to their results, bitumen solution was used to lessen the amount of asphaltene viscosity and in some occasions leads to the elimination the asphaltene precipitation from the small pores of bulk volume (Lesueur 2009; Mozaffari et al. 2015). They go on arguing that bitumen is directly affected the contact angle and the smallest amount of yield stress is a negative key parameter in distinguishing between Newtonian and non-Newtonian Bingham plastic behavior (Han et al. 2006; Saeed Mozaffari et al. 2017; Yang et al. 2016).

Underlying causes about the selection of appropriate acid are elaborated as the following reasons should be taken into consideration by engineers. These factors are permeability of the reservoir, original oil and gas in place, in-situ stress profile, reservoir skin factor, production background of the well from the beginning years of exploration, reservoir pressure and the saturation of each phase.

- Reservoir permeability: as it is evident, wells with the permeability of $10 \mathrm{mD}$ and above are more susceptible to the matrix acidizing operations, and the wells with permeability under one $\mathrm{mD}$ are considered as the best potential candidate for fracture acidizing.

- Productivity background of a well: by investigating the previous status of good productivity and its comparison with the adjacent drilled wells in the field, it gives engineers the chance to estimate more accurately and in some occasions may lead to decline in the acidizing procedures regarding the previous experiences of offset wells.

- Skin factor: the damages which are induced to the wells are considered as the skin effect and subsequently lead to permeability and productivity index reduction. This issue should be taken into consideration owing to the importance of this parameter. That is to say that, some wells which are suffering from skin effect aren't in urgent need of matrix acidizing and fracture acidizing might be the best candidate for them. Hence, this phenomenon should be adequately investigated because it may be seriously doubted on some occasions.

- Original oil and gas in place: the proper estimation of this parameter would enable engineers to decide better about the acidizing procedures due to the high expenditures of these operations. Thereby, those wells with the most substantial volume of oil and gas are the best selection for acidizing processes (Heydarabadi et al. 2010; Liu et al. 2017; Sylvester et al. 2015).

Well-testing operation is considered as the reservoir behavior analysis versus time alterations; in respect of the way, by utilizing the three variable parameters such as time, pressure and production or injection rate, most of the reservoir engineering parameters such as permeability, skin factor, surface well drainage (useful volume of well production), the type of reservoir (simple or complex) is obtained (Ahmadi et al. 2017; Jun and Minglu 2009; Prouvost and Economides 1987). Proper investigation of reservoir parameters played a significant role in stimulating an updated and beneficial reservoir model which could be used for explanation of reservoir porous media structure in order to enhance the productivity rate of a well. Several factors might be an obstacle to minimize the productivity rate of a well before and after drilling operations such as formation damage due to the drilling fluid penetration and cementing processes, and perforation procedures, well completion and damages which are applied by stimulation processes. The most noticeable method for enhancing the productivity rate and lessening the formation damage would be acidizing operations. Therefore, one of the chief aims of petroleum engineering programs is to increase the productivity rate of reservoirs by using acidizing operations. According to the wide variety of well-testing operations such as drawdown test, buildup test and their interpretation, it is possible to reach torrents of information about the reservoir and studied wellbore (Azamifard et al. 2016; Dai Weihua and Yuguo 2006; Xiaofen et al. 2009). In general, the purpose of each well-testing operations is to obtain useful information about well and the reservoir. For this purpose, wellbore flow rate has changed, and these alterations create a wavy pressure inside the reservoir. Therefore, measuring the pressure differences versus time and interpretation of these changes give some information about the well and reservoir (Zhao, Rui, Liao, and Zhang, 2015). Well-testing is a conditional and essential method in the petroleum and gas industry which can be utilized by the well-testing data analysis for decision making of petroleum companies investments worldwide. The most considerable appeal of well-testing operations is determination of the characteristics of the reservoir behavior, radius and type of reservoir behavior, optimum reservoir recovery and predicting reservoir behavior in the future and its possible problems which would occur in the reservoir or

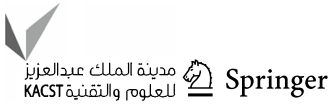


wellbore. If engineers do not pay attention to these issues, the productive life of reservoir and subsequently the efficient production of a reservoir will be limited (Bodin and Lopes, 2010).The well-testing model identification is a challenging task due to the non-uniqueness of the pressure responses generated by different reservoir models. The first step in the well-testing interpretation is to identify the underlying reservoir model by which model-related parameters could then be appropriately estimated using the appropriate conventional techniques. Hence, the well-testing analysis is an inverse solution; in respect of the way, many problems are still associated with the model selection, such as uncertain data and non-uniqueness of the pressure responses generated by different reservoir models. A schematic of the complete interpretation process depicts in Fig. 2. Many methods were used to consider the pressure response characteristic for partially perforated wells with apparent skin factor, such as conventional well-testing interpretation method with Horner method as the representation.

Although several studies are widely reported in the literature most of which are based on the profound impact of acidizing procedures, in this comprehensive study, we try to stimulate the reservoir with hydrochloric acid $15 \%$ and compare the results with the regular production operation. The optimum amount of acid is determined to enhance the productivity index and subsequently reduce the amount of skin factor.

Table 1 Formation data

\begin{tabular}{ll}
\hline Formation & Fahliyan \\
\hline Producing formation top & $14,202.00 \mathrm{ft}$. \\
Producing formation bottom & $14,317.58 \mathrm{ft}$. \\
Perforated interval top & $14,222.44 \mathrm{ft}$. \\
Perforated interval bottom & $14,271.65 \mathrm{ft}$. \\
Formation thickness & $115.49 \mathrm{ft}$. \\
Average formation porosity & 0.11 \\
Water saturation & 0.2 \\
Gas saturation & 0 \\
Formation compressibility & $4.6737 \mathrm{e}-6 \mathrm{psi}-1$ \\
Total system compressibility & $1.3453 \mathrm{e}-5 \mathrm{psi}-1$ \\
Layer pressure & $9592.991,136 \mathrm{psia}$ \\
Temperature & $267^{\circ} \mathrm{F}$ \\
Well radius & $0.2450 \mathrm{ft}$. \\
\hline
\end{tabular}

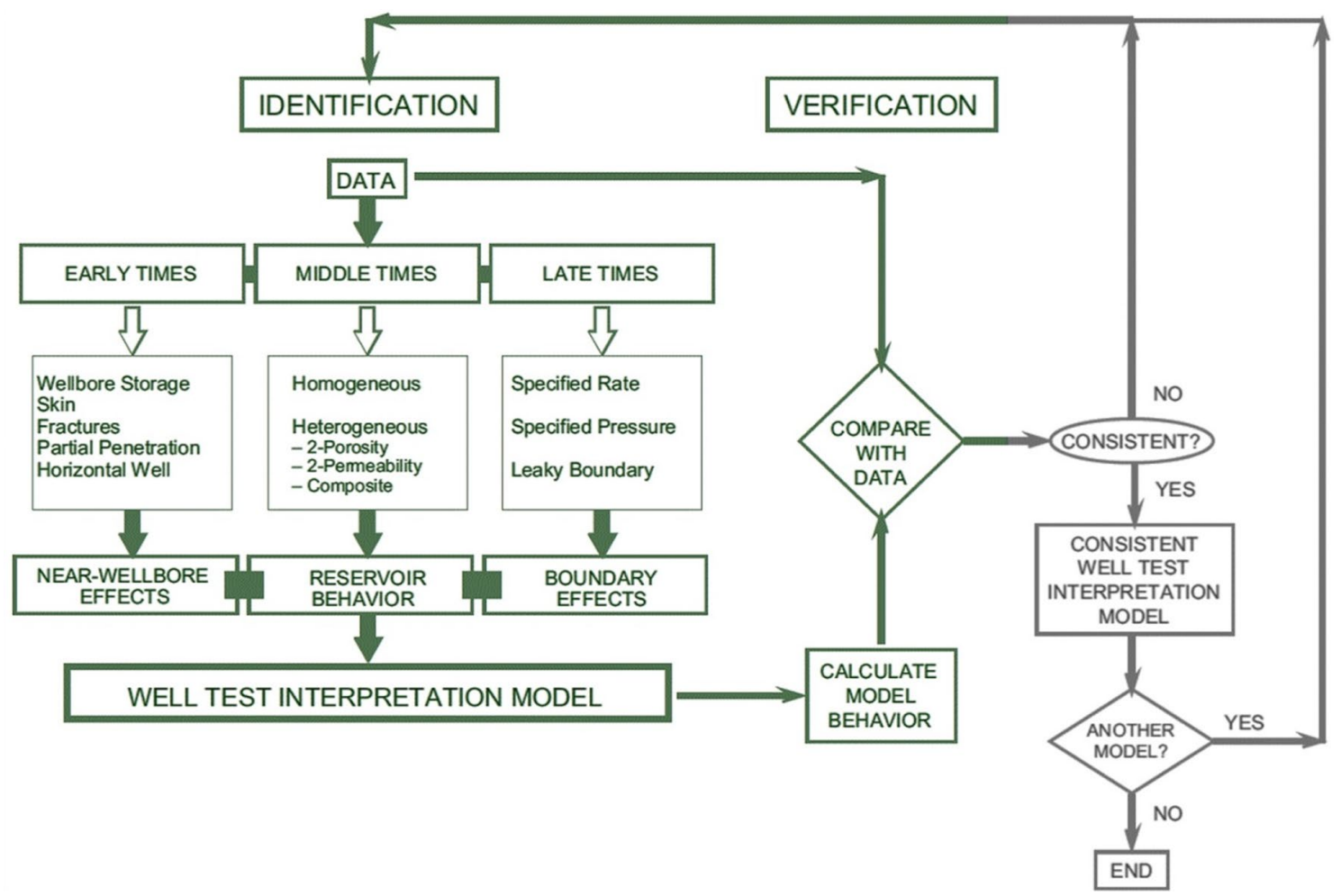

Fig. 2 Schematic of the complete interpretation process of well testing (Bodin and Lopes 2010) 
Table 2 Rock and fluid properties

\begin{tabular}{ll}
\hline Oil gravity & $39.5 \mathrm{API}$ \\
Gas gravity & $0.741 \mathrm{sp} . \mathrm{grav}$ \\
Gas-oil ratio (produced) & $1365 \mathrm{SCF} / \mathrm{STB}$ \\
Water cut & 0 \\
Water salinity & $0 \mathrm{ppm}$ \\
Check pressure & $9441 \mathrm{psia}$ \\
Check temperature & $267^{\circ} \mathrm{F}$ \\
Gas-oil ratio (solution) & $1365 \mathrm{SCF} / \mathrm{STB}$ \\
Bubble-point pressure & $5086.369 \mathrm{psia}$ \\
Oil density & $38.4514 \mathrm{lb} . / \mathrm{ft}^{3}$. \\
Oil viscosity & $0.24,482 \mathrm{c} \cdot \mathrm{p}$ \\
Oil formation volume factor & $1.70,006 \mathrm{RB} / \mathrm{STB}$ \\
Gas density & $19.0219 \mathrm{lb} . / \mathrm{ft}^{3}$. \\
Gas viscosity & $0.0,364,314 \mathrm{c} . \mathrm{p}$ \\
Gas formation volume factor & $2.9747 \mathrm{e}-3 \mathrm{ft}^{3} . / \mathrm{scf}$ \\
Water density & $59.1516 \mathrm{lb} . / \mathrm{ft}^{3}$ \\
Water viscosity & $0.18,593 \mathrm{c} . \mathrm{p}$ \\
Water formation volume factor & $1.05,435 \mathrm{RB} / \mathrm{STB}$ \\
Oil compressibility & $1.0177 \mathrm{e}-5 \mathrm{psia}^{-1}$. \\
Initial gas compressibility & $4.3687 \mathrm{e}-5 \mathrm{psia}^{-1}$. \\
\hline
\end{tabular}

\section{Methodology}

\section{Field Description}

The properties of studied well such as formation data, rock and fluid properties illustrate statistically in Tables 1 and 2.

\section{Reservoir Evaluation Steps}

1. Experimental design due to the reservoir fluid (oil or gas) an appropriate empirical evaluation must be designed.

2. Required instruments and tools for the experiment in this comprehensive study, DST tools are being used.

3. Data gathering one of the positive things in the final results and future reservoir estimation would be the accuracy of data gathering.

4. Experiment analysis after proper data gathering owing to types of applied tests, required parameters were calculated by mathematical formulation and then analyze the data. To do this process, Sapphire and Stimcade software are used.

5. Data interpretation it is the main part of each wellbore experimental tests.
Table 3 Properties of equipment in perforation operation

\begin{tabular}{ll}
\hline Perforation Depth & $14,222-14,271 \mathrm{ft}$. \\
Liner size & 7 inch \\
Perforation string & $3 \frac{1}{2}$ inch \\
Inclination & 90 degree \\
Applied pressure & $1200 \mathrm{psia}$ \\
Tubing & $3 * 27 / 8$ inch \\
Pressure in test pipe & $1000 \mathrm{psia}$ \\
Pressure in annulus & $2000 \mathrm{psia}$ \\
Choke size & $32 / 64$ inch \\
\hline
\end{tabular}

Table 4 Result of buildup pressure test

\begin{tabular}{lll}
\hline \multicolumn{3}{l}{ Semi-log line (buildup test) } \\
\hline From & 61.48 & $\mathrm{hr}$. \\
To & 64.44 & $\mathrm{hr}$. \\
Slope & 365.2 & $\mathrm{psi}$ \\
Intercept & 9618 & $\mathrm{psia}$ \\
P@ 1 h & 9193 & $\mathrm{psia}$ \\
P Match & 0.003 & psia $^{-1}$. \\
K.h & 429 & $\mathrm{mD} . \mathrm{ft}$. \\
K & 3.71 & $\mathrm{md}$ \\
p* & 9618 & $\mathrm{psia}$ \\
Skin & 7.79 & - \\
$\Delta$ P Skin & 2471 & $\mathrm{psi}$ \\
\hline
\end{tabular}

Table 5 Obtained data from buildup pressure test analysis after acidizing operation (test parameters)

\begin{tabular}{ll}
\hline Test type & Standard \\
Fluid type & Oil \\
Rate type & Surface rates \\
$\mathrm{r}_{\mathrm{w}}$ & $0.20,833 \mathrm{ft}$. \\
$\mathrm{h}$ & $115.49 \mathrm{ft}$. \\
\hline
\end{tabular}

\section{Results and Discussion}

\section{Well-testing procedure}

DST procedures in Fahliyan Formation in the depth range of 14,222-14,271 feet are operated, and the main purpose is to obtain reservoir properties in these depths. After that wellbore productivity rate evaluation is done by calculating productivity index and taking a sample from production wellbore. In this part of study, after finishing the drilling operation, perforating operation was done according to the required equipment which provides its information in Table 3.

Buildup pressure test is performed for $6 \mathrm{~h}$. According to Table 4, the amount of skin factor after acidizing operations measured 7.79. Thereby, this measurement explained the 
Table 6 Obtained data from buildup pressure test analysis after acidizing operation (PVT parameters)

\begin{tabular}{ll}
\hline Oil Volume Factor & $1.67,197 \mathrm{bbl} . / \mathrm{STB}$ \\
Viscosity & $0.247,228 \mathrm{c.p}$ \\
Total Compressibility & $1.47 \mathrm{E}-05 \mathrm{psia}^{-1}$ \\
\hline
\end{tabular}

Table 7 Obtained data from buildup pressure test analysis after acidizing operation (main model parameters)

\begin{tabular}{ll}
\hline T Match & $50.9 \mathrm{~h}^{-1}$ \\
P Match & $0.0014 \mathrm{~h}^{-1}$ \\
$\mathrm{C}$ & $0.00,893 \mathrm{bbl} . /$ Psia \\
Total skin & -3.34 \\
$\mathrm{~K} \mathrm{~h}$ & $381 \mathrm{mD} . \mathrm{ft}$. \\
$\mathrm{K}_{\text {average }}$ & $3.3 \mathrm{mD}$ \\
$\mathrm{Pi}$ & 9583.98 Psia \\
\hline
\end{tabular}

Table 8 Obtained data from buildup pressure test analysis after acidizing operation parameters) (reservoir and boundary

\begin{tabular}{ll}
\hline $\mathrm{Pi}$ & 9583.98 psia \\
K.h & $381 \mathrm{mD} . \mathrm{ft}$. \\
$\mathrm{k}$ & $3.3 \mathrm{mD}$ \\
$\mathrm{r}_{\mathrm{i}}$ & $246 \mathrm{ft}$. \\
$\mathrm{M}$ & 0.694 \\
$\mathrm{D}$ & 0.635 \\
\hline
\end{tabular}

Table 9 Obtained data from buildup pressure test analysis after acidizing operation (derived and secondary parameters)

\begin{tabular}{ll}
\hline Delta Q & $4650 \mathrm{STB} / \mathrm{D}$ \\
$\mathrm{P} @ \mathrm{dt}=0$ & $6670 \mathrm{Psia}$ \\
$\mathrm{k} / \mathrm{mu}$ & $13.3 \mathrm{mD} / \mathrm{c} \mathrm{p}$ \\
Delta P (total skin) & $-2380 \mathrm{psia}$ \\
Delta P ratio (total skin) & $-0.858,586$ (fraction) \\
\hline
\end{tabular}

damage in the perforated area. Due to having skin effect in the wellbore, a pressure difference is calculated 2471 psia. Hence, this pressure difference must be modified during the acidizing operations.

Conversely, this well takes the production experiment and buildup pressure test again and the results of related graphs owing to hydrochloric acid $15 \%$ with injecting 4000 gallons are depicted in Tables 5, 6, 7, 8 and 9.

The amount of skin factor after acidizing operations plummeted from 7.79 to -3.34 . Thereby, this decrease in skin factor leads to pressure difference reduction from 2470 psia to -2380 psia; this is why acidizing performances either remove the skin effect or enhance the productivity power of the well dramatically. To analyze the wellbore productivity power and calculate the productivity index, wellbore model is simulated in Prosper software. IPR curves are being plotted before and after acidizing operations as shown in Figs. 3, 4.

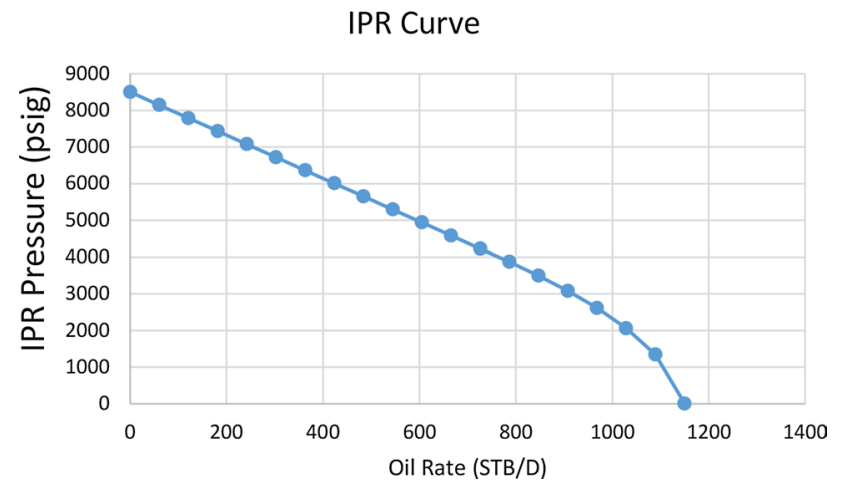

Fig. 3 The accelerating pace of productivity rate before acidizing (IPR curve)

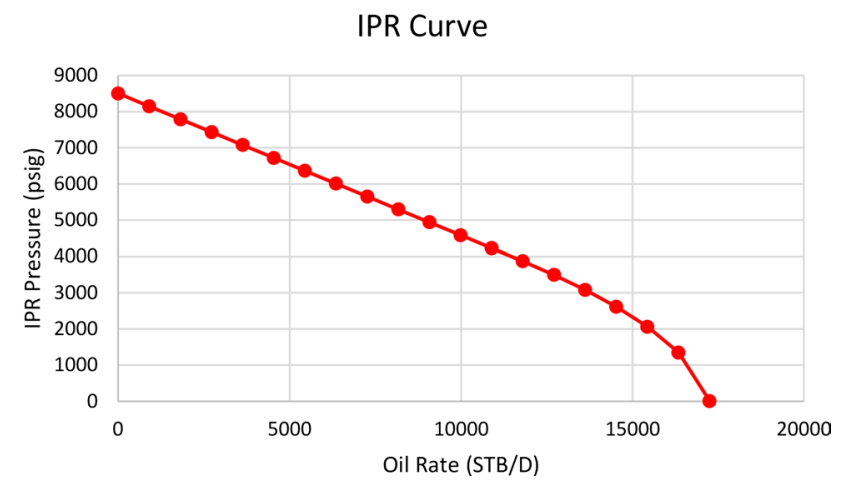

Fig. 4 The accelerating pace of productivity rate after acidizing (IPR curve)

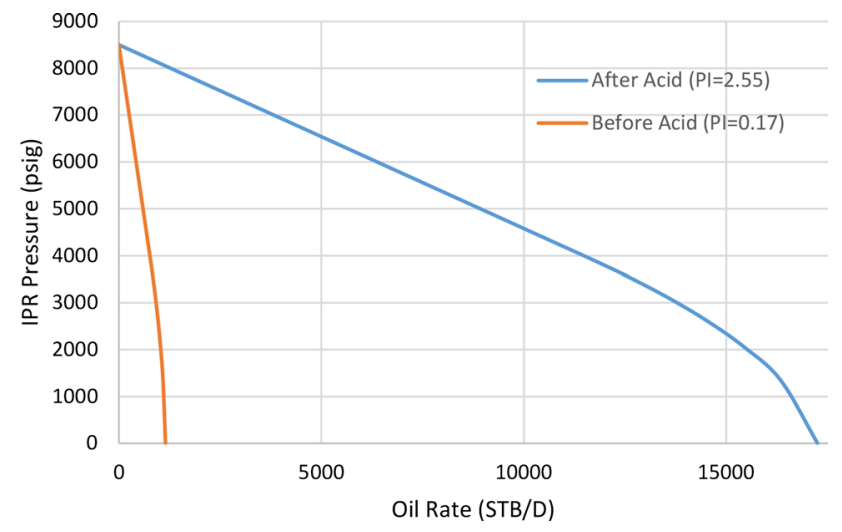

Fig. 5 Comparison of the accelerating pace of productivity rate before and after acidizing (IPR curve)

As it is clarified in Figs. 3, 4, the amount of productivity index before acidizing operation and Absolute Open Flow are $0.49 \mathrm{STBD} / \mathrm{psi}$ and $3642 \mathrm{STBD} /$ day, respectively. These quantities are calculated as $1.55 \mathrm{STBD} / \mathrm{psi}$ and 11,352 STBD/day, respectively after acidizing. 
In Fig. 5, the comparison of accelerating the pace of productivity rate before and after acidizing for IPR curve is drawn. As can be seen in Fig. 5, appropriate acidizing procedures improve the well efficiency which leads to enhancing the liquid rate. Thereby, it has a steep rise in the flow rate by passing the drilling time.

\section{Acidizing procedures in studied Field}

After analyzing the buildup pressure test in this well, the skin factor in this perforation interval is being investigated as 7.79. That is to say that, this amount reveals the severe damage regarding perforation operations. According to these results, acidizing operations by utilizing moveable tubing with an injection of 4000 gallons of hydrochloric acid $15 \%$ and provided additives in Table 10 are being done.

Table 10 Concentration of additives in acidizing operation

\begin{tabular}{ll}
\hline Additive type & $\begin{array}{l}\text { Concen- } \\
\text { tration } \\
(\%)\end{array}$ \\
\hline 15\% HCl & 92.2 \\
Inhibitor aid & 3.2 \\
Mutual solvent & 0.7 \\
Corrosion inhibitor & 2 \\
Dispersing agent & 1.5 \\
Anti-sludge & 0.2 \\
H2S scavenger & 0.4 \\
Iron control agent & 0.7 \\
Surfactant & 0.2 \\
\hline
\end{tabular}

According to the performed investigations, the possible damage to the specified interval owing to drilling history is of mixed deposits type with the combination of 50 percent of solvent, and the remaining percentage of non-soluble in acid is analyzed. Acid injection in this field is done by the method of full-bore DST and by pumping from the surface. Regarding acidizing operation, the acid injected rate is approximately $1.2-1.9 \mathrm{bbl} . / \mathrm{min}$ and the pressure of $3800-6600 \mathrm{psia}$. This high rate of injection demonstrates the inappropriate rate of injection in the perforated area. Surficial and wellbore Pressure changes of acid injection versus time are depicted in Fig. 6.

Due to the lack of expeimental information about the proper rate of acid injection in each step about simulated processes, estimated wellbore injected pressure by considering obtained flow rate and abnormal reservoir rock condition take out of the limited allowance of breaking interval, injected acid with the derived flow rate of $1.2 \mathrm{bbl} . / \mathrm{min}$ do not be possible. Therefore, by assuming 10 barrel of acid for creating permeability and initial injection with a minimum flow rate of $0.2 \mathrm{bbl} . / \mathrm{min}$, this restriction virtually eliminated. Furthermore, when the primary acid volume is injected to the wellbore, in the next stage, the injection of remained acid with the rate of $18 \mathrm{bbl} . / \mathrm{min}$ regarding the allowable pressure on the formation is operated. In this study, by using Stimcade software due to well-testing analysis in this wellbore, skin factor after acidizing operations is calculated -4.41 ; in respect of the way, the results of performed analysis illustrated that by simulating 4000 -gallon acid, estimated model is fundamentally similar to the real condition of the well.

According to Fig. 7, the maximum amount of skin factor reduction by injecting 20 barrel of initial acid ( 420 gallons)

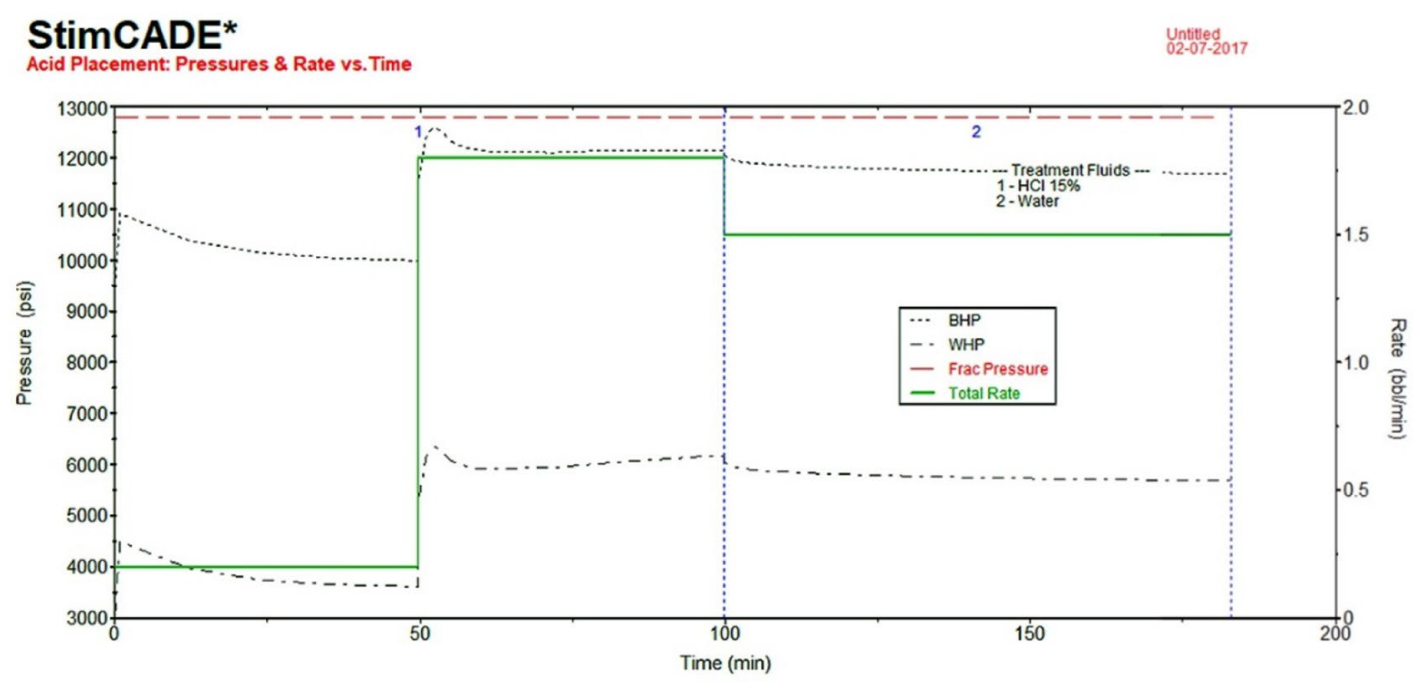

-Mark of Schlumberaer

Schlumberger

Fig. 6 Surficial and wellbore pressure changes of acid injection versus time 
StimCADE*

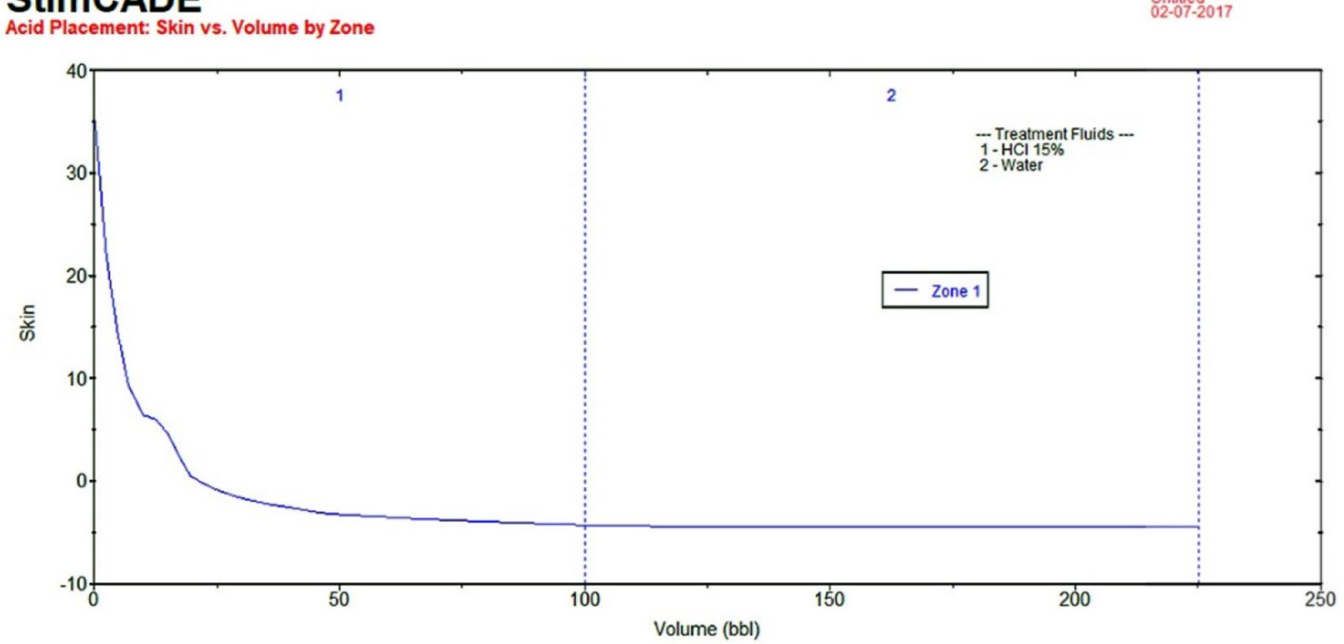

'Mark of Schlumberger

Schlumberger

Fig. 7 Skin factor changes regarding volume of acid injection

\section{StimCADE*}

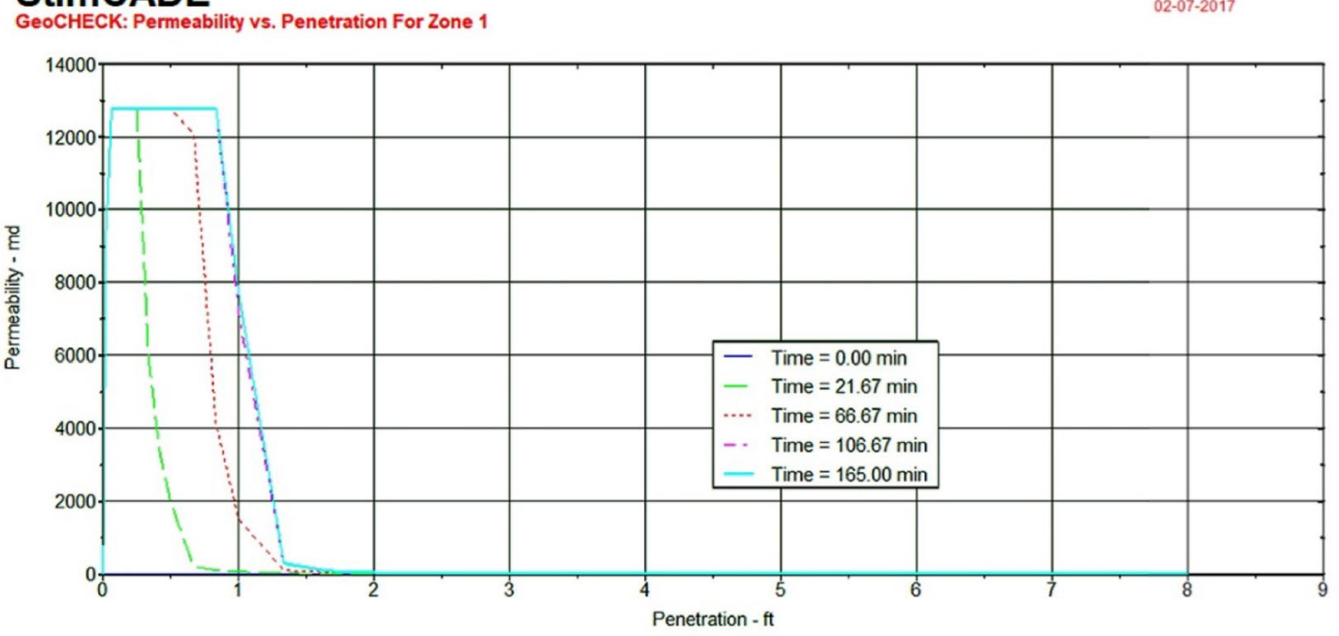

"Mark of Schlumberaer

Fig. 8 Permeability changes versus acid penetration depth

is occurred. After acid injection, the amount of skin factor is decreased from 7.79 to zero. That is to say that, regarding drilling and perforation operation, the damaged area of the reservoir is less deep than before. The remaining volume of injected acid is gradually help to lessen the amount of skin factor and enhance the physical properties of reservoir rock such as porosity and permeability.

According to Fig. 8, before acidizing the amount of permeability in the depth of 0.04 foot is equal to 0.5 milli Darcy (regarding damages are applied by perforation and drilling operation) and in the far side of the wellbore is equivalent to 3.2 milli Darcy. This amount is dramatically improved to 1755 milli Darcy by contacting acid over a period of $30 \mathrm{~min}$. By injecting more acid volumes, the permeability has been increased. It is a foregone conclusion that closer areas of the wellbore have more alteration in permeability rather than far points.

According to Fig. 9 in the starting time of injection, porosity is measured $6 \%$. This amount has reached the peak (approximately 95\%) and has its high quantity by injecting 


\section{StimCADE*}

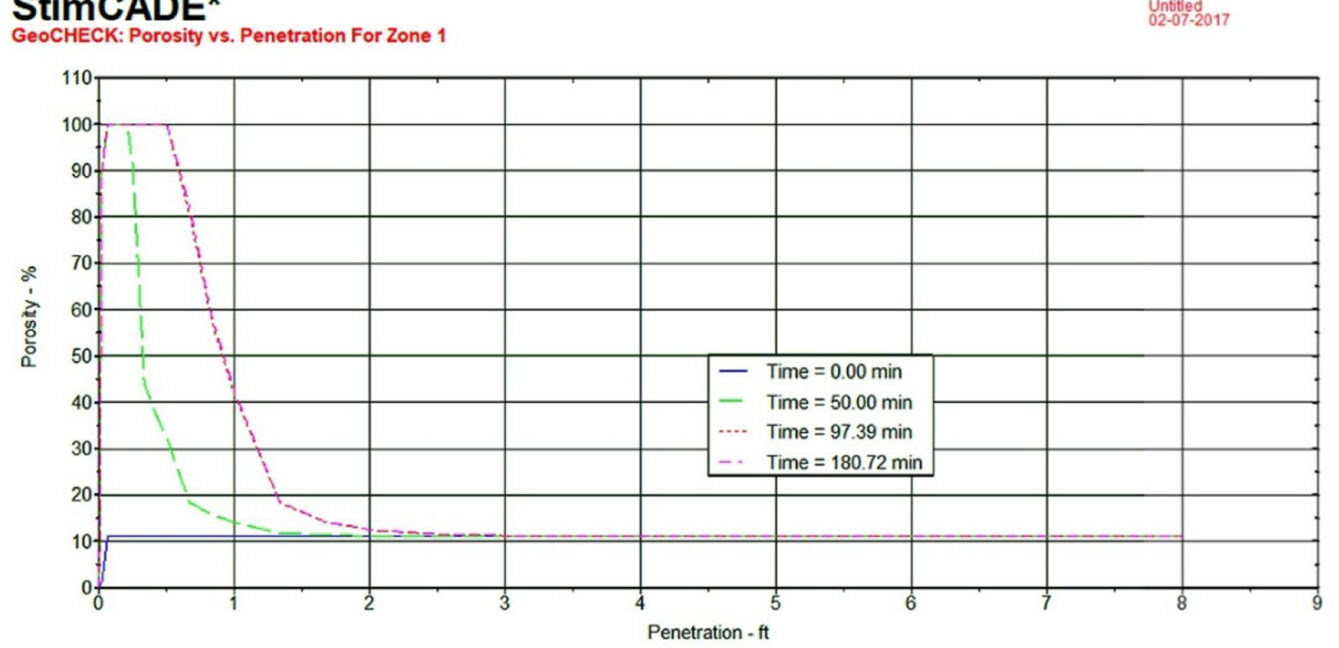

Mark of Schlumberger

Schlumberger

Fig. 9 Porosity alterations versus acid penetration depth

\section{StimCADE*}

GeoCHECK: Pressure vs. Penetration For Zone 1

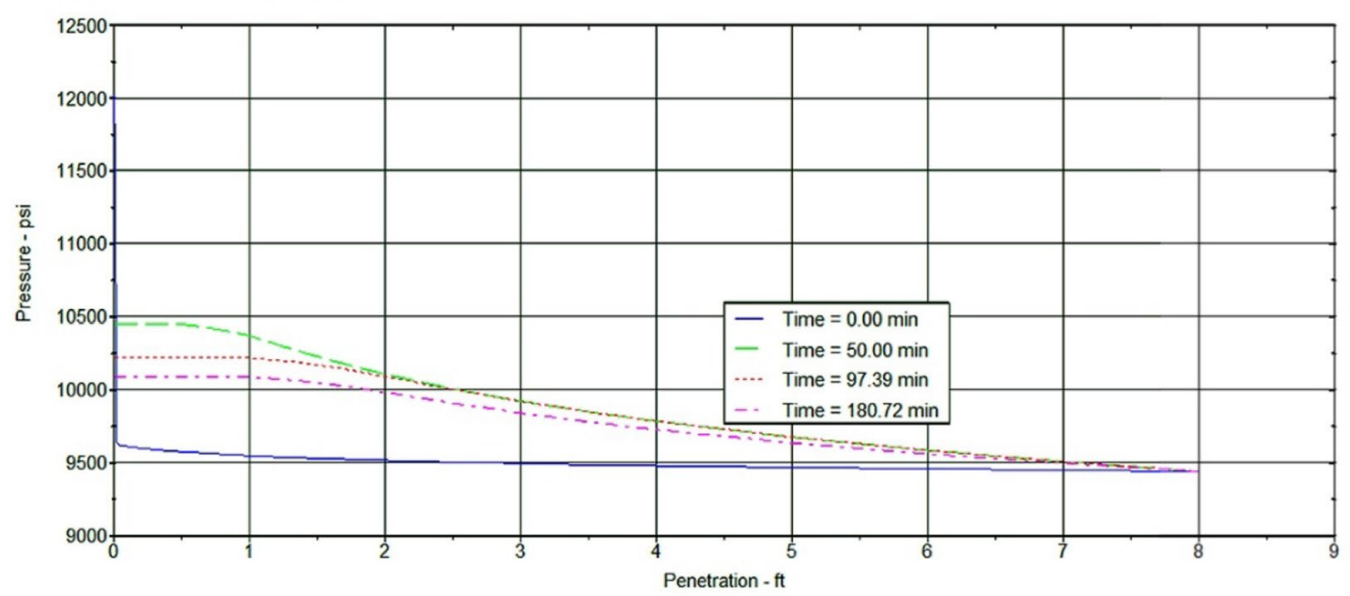

'Mark of Schlumberger

Fig. 10 Pressure differences versus acid penetration depth

10 barrel of acid over a period of $30 \mathrm{~min}$. Created tunnels are propagated up to the depth of 0.5 foot (with a porosity of $100 \%$ ), and after that, it falls slightly. Finally, in the depth of 3 foot from the wellbore owing to reaction with acid, the percentage of porosity is being increased about 11 percent instead of initial reservoir porosity.

According to Fig. 10 in the starting time of injection owing to low permeability around the wellbore, wellbore injection pressure is about $12,000 \mathrm{psia}$. This amount is dramatically reduced to 9500 psia by contacting acid over a period of $30 \mathrm{~min}$. Since then, by injecting 10 barrel of initial acid, wellbore contacting pressure reduced to 10,300 psia. Therefore, reservoir pressure profile penetrates up to the depth of $7 \mathrm{foot}$; in respect of the way, due to the low permeability of reservoir rock, it increased the fluid flow to the wellbore. 


\section{Suggestions and Future research}

i. Although the procedure of selecting acid formulation requires comparative experimental tests, it is highly recommended that this experimental evaluation is administered by taking cores from the wellbore or its cutting and the applied tubing in the wellbore drill string with different concentrations of hydrochloric acid (such as 5,10,20 and 28\%). Therefore, it enrolled the engineers to utilize several designations among production operation.

ii. According to the simulated model by the software, an increase in the amount of acid concentration regarding low injection rate to the formation do not cause an increase in the penetration depth. Furthermore, raising the volume of used acid is being investigated in this operation. Hence, it is suggested that water-flooding operations with acid could be applied for observing the rocking behavior against injected acid.

iii. Regarding low permeability in the full-bore DST, increasing the amount of injected pressure due to increasing amount of injected rate is suggested; in respect of the way, these procedures need the appropriate studies owing to determining the formation fracture gradient.

\section{Conclusion}

One of the chief aims of this comprehensive study is to investigate the efficiency of acidizing procedures in Fahliyan formation by utilizing hydrochloric acid $15 \%$ and its comparison with simulated acidizing operation model. To obtain required information regarding wellbore and formation physical properties, it is necessary that the proper evaluation of the wellbore is being done before and after the acidizing procedures. Some of the physical features of the studied field such as reservoir pressure, permeability and skin factor are extracted from full-bore DST tests. In this experiment, after operating two buildup test before and after acidizing the amount of skin factor are 7.79 and -3.34 , respectively. Regarding output of simulation processes, the amount of skin factor after acidizing operation related to full-bore DST is calculated as 4.41 which has acceptable relevance to buildup analysis experiment. Consequently, after acidizing procedure, productivity rate has a dramatic change from $0.57 \mathrm{STBD} / \mathrm{psi}$ to $1.55 \mathrm{STBD} / \mathrm{psi}$.

Open Access This article is distributed under the terms of the Creative Commons Attribution 4.0 International License (http://creativeco mmons.org/licenses/by/4.0/), which permits unrestricted use, distribution, and reproduction in any medium, provided you give appropriate credit to the original author(s) and the source, provide a link to the Creative Commons license, and indicate if changes were made.

\section{References}

Ahmadi R, Aminshahidy B, Shahrabi J (2017) Well-testing model identification using time-series shapelets. J Petrol Sci Eng 149:292-305

Al-Muhareb MA, Nasr-El-Din HA, Samuel E, Marcinew RP, Samuel M (2003) Acid fracturing of power water injectors: a new field application using polymer-free fluids. Paper presented at the SPE European Formation Damage Conference

Azamifard A, Hekmatzadeh M, Dabir B (2016) Evaluation of gas condensate reservoir behavior using velocity dependent relative permeability during the numerical well test analysis. Petroleum 2(2):156-165

Babaei M, Sedighi M (2017) Impact of phase saturation on wormhole formation in rock matrix acidizing. Chem Eng Sci

Barati R, Liang JT (2014) A review of fracturing fluid systems used for hydraulic fracturing of oil and gas wells. J Appl Polym Sci 131(16)

Bodin D, Lopes OM (2010) Modeling heat flux calculations in surface well-testing operations. J Petrol Sci Eng 72(1):18-32

Chengshou C, Yaogang Z, Haomin J, Qiangjun W, Fajun R, Zhi L, Lei L (2010) New stimulation technologies on horizontal wells in Jingbian gas fields. Nat Gas Ind 7:020

Dai Weihua YJWM, Yuguo Z (2006) Streamline numerical well test interpretation model. Acta Petrolei Sinica 3:021

Davarpanah A, Mirshekari B, Jafari Behbahani T, Hemmati M (2018) Integrated production logging tools approach for convenient experimental individual layer permeability measurements in a multi-layered fractured reservoir. J Petrol Explor Prod Technol. https://doi.org/10.1007/s13202-017-0422-3

Fufeng G, Liqiang Z, Pingli L (2008) Overview of acidizing technology of horizontal well. Fault-Block Oil \& Gas Field 1:042

Garrouch AA, Jennings AR Jr (2017) A contemporary approach to carbonate matrix acidizing. J Petrol Sci Eng 158:129-143

Ghommem M, Zhao W, Dyer S, Qiu X, Brady D (2015) Carbonate acidizing: modeling, analysis, and characterization of wormhole formation and propagation. J Petrol Sci Eng 131:18-33

Ghommem M, Qiu X, Brady D, Al-Tajar F, Crary S, Mahjoub A (2016) Monitoring of matrix acidizing by using resistivity measurements. Paper presented at the SPE Annual Technical Conference and Exhibition

Guimarães MS, Grana TDA, Sarkis M, Raider S (2017) Study and simulation of matrix acidizing in sandstones reservoirs applied to injection wells of the mature fields. Paper presented at the SPE Latin America and Caribbean Mature Fields Symposium

Han A, Mondin G, Hegelbach NG, de Rooij NF, Staufer U (2006) Filling kinetics of liquids in nanochannels as narrow as $27 \mathrm{~nm}$ by capillary force. J Colloid Interface Sci 293(1):151-157. https ://doi.org/10.1016/j.jcis.2005.06.037

Hassani A, Kamali MR (2017) Optimization of acid injection rate in high rate acidizing to enhance the production rate: an experimental study in Abteymour oil field, Iran. J Petrol Sci Eng 156:553-562

Heydarabadi FR, Moghadasi J, Safian G, Ashena R (2010) Criteria for selecting a candidate well for hydraulic fracturing. Paper presented at the Nigeria Annual International Conference and Exhibition

Hung K, Hill A, Sepehrnoori K (1989) A mechanistic model of wormhole growth in carbonate matrix acidizing and acid fracturing. $\mathrm{J}$ Petrol Technol 41(01):59-66

Jun Y, Minglu W (2009) Streamline numerical well-testing interpretation model and pressure response for partially perforated wells. Petroleum Exploration and Development 36(4):513-518

Khalil RE, Mansour A, Gamadi T (2017) An experimental study of acid matrix treatment performance on shale core samples. Paper 
presented at the SPE Liquids-Rich Basins Conference-North America

Lesueur D (2009) The colloidal structure of bitumen: consequences on the rheology and on the mechanisms of bitumen modification. Adv Coll Interface Sci 145(1):42-82. https://doi.org/10.1016/j. cis.2008.08.011

Li N, Dai J, Liu P, Luo Z, Zhao L (2015) Experimental study on influencing factors of acid-fracturing effect for carbonate reservoirs. Petroleum 1(2): 146-153

Liu P, Yao J, Couples GD, Ma J, Huang Z, Sun H (2017) Modeling and simulation of wormhole formation during acidization of fractured carbonate rocks. J Petrol Sci Eng 154:284-301

Medina E, Sierra J, Garcia A, Gleaves J, Mendez J (2015) Optimization of matrix acidizing with fluids diversion in real-time using distributed temperature sensing and coiled tubing. Paper presented at the SPE/ICoTA coiled tubing \& well intervention conference and exhibition

Mozaffari S, Tchoukov P, Atias J, Czarnecki J, Nazemifard N (2015) Effect of asphaltene aggregation on rheological properties of diluted athabasca bitumen. Energy Fuels 29(9):5595-5599

Mozaffari S, Tchoukov P, Mozaffari A, Atias J, Czarnecki J, Nazemifard N (2017) Capillary driven flow in nanochannels: application to heavy oil rheology studies. Colloids Surf A 513:178-187

Msharrafieh M, Al-Ghoul M, Sultan R (2006) Simulation of geochemical banding in acidization-precipitation experiments in situ. World Scientific, Singapore

Msharrafieh M, Al-Ghoul M, Zaknoun F, El-Rassy H, El-Joubeily S, Sultan R (2016) Simulation of geochemical banding I: acidization-precipitation experiments in a ferruginous limestone rock. Chem Geol 440:42-49

Prouvost LP, Economides MJ (1987) Real-time evaluation of matrix acidizing treatments. J Petrol Sci Eng 1(2):145-154
Qi N, Li B, Chen G, Fang M, Li X, Liang C (2017) Optimum fluid injection rate in carbonate acidizing based on acid dissolution morphology analysis. Energy Fuels

Sanyal S, Marsden Jr S, Ramey Jr H (1974) Effect of temperature on petrophysical properties of reservoir rocks. Paper presented at the SPE California regional meeting

Schön JH (2015) Physical properties of rocks: Fundamentals and principles of petrophysics, vol 65. Elsevier

Sylvester O, Bibobra I, Augustina O (2015) A method for stimulation candidate well selection. Int J Eng Technol 5(1)

Tiab D, Donaldson EC (2015) Petrophysics: theory and practice of measuring reservoir rock and fluid transport properties. Gulf Professional Publishing

Wang Y, Hill A, Schechter R (1993) The optimum injection rate for matrix acidizing of carbonate formations. Paper presented at the SPE Annual Technical Conference and Exhibition

Xiaofen T, Yuzhang L, Limin Y, Falin W, Tao M, Hongwei M (2009) Laboratory researches on deep fluid diversion agent with high strength and retarding swelling characteristics. Pet Explor Dev 36(4):494-497

Yang M, Cao B-Y, Wang W, Yun H-M, Chen B-M (2016) Experimental study on capillary filling in nanochannels. Chem Phys Lett 662:137-140. https://doi.org/10.1016/j.cplett.2016.09.016

Yu M, Mahmoud MA, Nasr-El-Din HA (2011) Propagation and retention of viscoelastic surfactants following matrix-acidizing treatments in carbonate cores. SPE J 16(04):993-1001

Zhao X, Rui Z, Liao X, Zhang R (2015) A simulation method for modified isochronal well testing to determine shale gas well productivity. J Natl Gas Sci Eng 27:479-485 